\title{
O MOTOTAXISMO COMO EXEMPLO DE UM NOVO DESAFIO PARA O TRANSPORTE: A INTEGRAÇÃO DO DESENVOLVIMENTO SUSTENTÁVEL E TERRITÓRIO COMO MODELO ECONÔMICO INCLUDENTE
}

\author{
Emerson Gervásio de Almeida ${ }^{1}$ \\ Ronaldo de Souza Neves ${ }^{2}$ \\ William Rodrigues Ferreira ${ }^{3}$
}

\section{RESUMO}

O presente trabalho aborda como a sociedade contemporânea enfrenta a crise do crescimento e a necessidade de um novo conceito de desenvolvimento, de caráter sistêmico e que compatibilize globalização, crescimento econômico e tecnológico com a eqüidade, o desenvolvimento humano e a sustentabilidade ambiental. Esse o grande desafio para o transporte, tudo tendo como base o mototaxismo. A análise da atual situação econômica apresenta-se como possível solução para o problema da integração entre território e o desenvolvimento sustentável, também conhecido como ecossociodesenvolvimento ou desenvolvimento integral, consistente em um novo modelo, que inclui os atores sociais e os considera catalisadores das atividades produtivas, tudo na ótica da garantia da universalização dos direitos fundamentais. Trata-se de uma política de planejamento inspirada na cooperação e nos processos endógenos de construção, que aumentam o sentimento de pertencimento das comunidades, potencializando a produção e racionalizando as ações público-privadas, que se tornam mais eficazes, menos burocráticas, e com aplicabilidade concreta na estrutura econômica vigente. Para tanto, a metodologia utilizada baseou-se em levantamento bibliográfico apurado e análise de dados coletados.

Palavras-chave: Desenvolvimento sustentável. Transporte. Economia. Território. Inclusão social.

\footnotetext{
1 Professor efetivo da Universidade Federal de Goiás - UFG e mestrando do curso de pós-graduação em Geografia da Universidade Federal de Uberlândia - UFU. Email: emersongervasio@yahoo.com.br

${ }^{2}$ Graduando em Direito pela Fundação Educacional de Ituiutaba - FEIT, Campus Fundacional da Universidade do Estado de Minas Gerais - UEMG. Email: ronaldonevesbb@yahoo.com.br

3 Professor doutor do Instituto de Geografia da Universidade Federal de Uberlândia - UFU. Email: wferreira@ufu.br
} 


\begin{abstract}
This papper discusses how the contemporary society faces the crisis of the growth and the need for a new concept of development, systematic character and to reconcile globalization, economic and technological growth with equity, human development and environmental sustainability. That is the great challenge for the transport, all bases on the mototaxis. The analysis of the current economic situation presents itself as a possible solution to the problem of integration between territory and the sustainable development, also known as ecossocialdevelopment or integral, solid, full development, consisting of a new model, which includes social actors and considers a catalyst for productive activities, everything from the viewpoint of ensuring the universality of basic, fundamental rights. It's a planning politics inspired by cooperation and endogenous processes of construction, which increase the feeling of belonging communities, enhancing the production and rationalize the actions of privatepublic partnerships, which become more effective, less bureaucratic, and applicability concrete in the existing economic structure. Therefore, the methodology used was based on established literature and analysis of data collected.
\end{abstract}

Key-words: Sustainable development. Transport. Economy. Territory. Social inclusion.

\title{
Introdução
}

A acumulação de riquezas com o propósito final do desenvolvimento é um paradigma que vem sendo alterado aos olhos da economia mundial. Os países latino-americanos, e até outras nações fixadas no estágio considerado desenvolvido, enfrentam uma severa crise da democracia econômica e social, que se configura, principalmente, pelo desemprego, a marginalização social, a exclusão, a segregação e o desequilíbrio ambiental. Não é diferente o caso do Brasil, cuja realidade constata que apenas o crescimento econômico não pode ser o objetivo último do desenvolvimento, e nem assegura, por si só, a melhoria da qualidade de vida das pessoas.

Nas palavras do economista Sachs (1993), criador dos fundamentos do debate contemporâneo sobre a necessidade de um novo paradigma de desenvolvimento, baseado na convergência entre economia, ecologia, antropologia cultural e ciência política, o mundo contemporâneo vive um crescimento através da desigualdade, que:

[...] provoca um aumento significativo na renda per capita, mas resulta no contra-desenvolvimento quando visto sob o ângulo da distribuição de renda, do acesso a recursos, da satisfação de necessidades básicas e, acima de tudo, da privação do direito ao trabalho - que é não apenas uma forma de garantir 
a sobrevivência, mas também um elemento fundamental para a integração social e para a dignidade humana. (SACHS, 1993, p. 10).

O desenvolvimento dos povos está inserido na terceira geração de direitos, de caráter coletivo, juntamente com o direito à infância, ao meio-ambiente, à cidade, reconhecidos na Conferência Mundial sobre Direitos Humanos de Viena (1993). Também as dimensões que compõem o núcleo do conceito de desenvolvimento - economia, espaço, saúde, educação, cultura e meio-ambiente - estão previstas pela Constituição da República de 1988, especificamente nos Capítulos "Da Ordem Econômica e Financeira" e "Da Ordem Social" (artigos 170, 174, 182, 184, 196, 197, 205, 215 e 255), que inserem, ainda, o conceito de sustentabilidade. Não basta o desenvolvimento atual, é preciso que ele seja sustentável, isto é, conforme o conceito do Relatório Nosso Futuro Comum (ou Relatório Brundtland, de 1987)4, desenvolvimento sustentável é aquele "que atende as necessidades do presente sem comprometer a possibilidade de as gerações futuras atenderem às suas próprias necessidades". Esses componentes são citados no relatório do Programa das Nações Unidas para o Desenvolvimento (1990 apud ZAPATA, 2006, s/p.), ao informar que

[...] o universalismo dos direitos da vida é o fio condutor comum, que une a busca do desenvolvimento humano, com as exigências do amanhã, especialmente com a necessidade de preservação e regeneração do meio ambiente para o futuro. Há uma necessidade ética de se garantir às gerações futuras oportunidades iguais às que gerações anteriores desfrutaram. Assim, desenvolvimento e sustentabilidade são componentes essenciais da mesma ética do universalismo dos direitos da vida, que exige também eqüidade para com a geração atual e as futuras.

Igualmente, quando se trata de geografia dos transportes, o tema desenvolvimento é bastante polêmico, posto que impróprio a designação deste termo se aliado à figura de congestionamentos, destruição de ecossistemas, segregação, tarifas impraticáveis. Em face desta realidade moderna, com a clareza e bom senso costumeiro, Souza (2005) nos deixa a seguinte lição:

[...] se a riqueza assim produzida e o crescimento da cidade se fazem às custas da destruição de ecossistemas inteiros e do patrimônio históricoarquitetônico; se a conta da modernização vem sob a forma de níveis cada vez menos toleráveis [...] de estresse, de congestionamentos [...] se é assim, falar de "desenvolvimento" é ferir o

bom senso. Pode-se, em tal caso, falar de crescimento urbano, complexificação da cidade e até mesmo modernização do espaço urbano e dos padrões de consumo; mas seria um equívoco tomar isso por um processo de desenvolvimento urbano autêntico [...]. (SOUZA, 2005, p. 101-102). 
4 Relatório Nosso Futuro Comum ou Relatório Brundtland - elaborado pela Comissão Mundial sobre o Meio Ambiente e Desenvolvimento, faz parte de uma série de iniciativas, as quais reafirmam uma visão crítica do modelo de desenvolvimento adotado pelos países industrializados e reproduzido pelas nações em desenvolvimento, e que ressaltam os riscos do uso excessivo dos recursos naturais sem considerar a capacidade de suporte dos ecossistemas.

Ainda quanto à importância deste tema, continua asseverando Souza (2005) que:

Um desenvolvimento urbano autêntico, sem aspas, não se confunde com uma simples expansão do tecido urbano e a crescente complexidade deste, na esteira do crescimento econômico e da modernização tecnológica. Ele não é, meramente, um aumento da área urbanizada, e nem mesmo, simplesmente, uma sofisticação ou modernização do espaço urbano, mas, antes e acima de tudo, um desenvolvimento sócio-espacial na e da cidade: vale dizer, a conquista de melhor qualidade de vida para um número crescente de pessoas e de cada vez mais justiça social. (SOUZA, 2005, p. 101).

Diante da problemática que envolve o trânsito e o transporte brasileiros, sob a ótica do mototaxismo, aliado à forma desordenada de desenvolvimento de nossas cidades, faz-se necessário abordar o novo conceito de desenvolvimento (desenvolvimento integral ou sistêmico), que defende e promove a adoção de políticas públicas que consideram as pessoas, e não a acumulação de riquezas, como o propósito final do desenvolvimento, alinhado à sustentabilidade como ponto chave para o seu alcance.

\section{Sustentabilidade urbana}

A necessidade de se criar um modelo de desenvolvimento sustentável não parece ser injustificada. O século XXI iniciou com uma exigência fundamental: como compatibilizar a globalização, o crescimento econômico e tecnológico com a eqüidade, o desenvolvimento humano e a sustentabilidade ambiental? Debates sobre essa questão têm mobilizado os mais diferentes setores da comunidade em geral, sendo consenso de que esses pilares devem ser observados de forma equilibrada. Dessa forma, sustentabilidade é um conceito sistêmico, relacionado com a continuidade dos aspectos econômicos, sociais, culturais e ambientais da sociedade humana. Propõe-se a ser um meio de configurar a civilização e a atividade humana, de tal forma que a sociedade, os seus membros e as suas economias possam preencher as suas necessidades e expressar o seu maior potencial no presente, e ao mesmo tempo preservar a biodiversidade e os ecossistemas naturais, planejando e agindo de forma a atingir próeficiência na sua manutenção. 
A sustentabilidade abrange vários níveis de organização, desde a vizinhança local até o restante do planeta. Para um empreendimento humano ser sustentável, tem que se ter em vista quatro requisitos básicos: o empreendimento deve ser ecologicamente correto, economicamente viável, socialmente justo e culturalmente aceito. Portanto, a sustentabilidade requer uma abordagem sistêmica que integre os aspectos ambiental, econômico, social e cultural, dimensões que denotam as preocupações do verdadeiro desenvolvimento.

Em sua obra "Caminhos para o desenvolvimento sustentável”, o já mencionado economista Ignacy Sachs (2002) apresenta os critérios que devem ser observados para que seja alcançada a sustentabilidade:

a) Social: abrange o alcance de um patamar razoável de homogeneidade social; distribuição de renda justa; o emprego pleno e/ou autônomo com qualidade de vida decente; e a igualdade no acesso aos recursos e serviços sociais; b) Cultural: mudanças no interior da continuidade (equilíbrio entre respeito à tradição e inovação); a capacidade de autonomia para elaboração de um projeto nacional integrado e endógeno (em oposição às cópias servis dos modelos alienígenas); e autoconfiança combinada com abertura para o mundo; c) Ecológica: inclui a preservação do potencial do capital natureza na sua produção de recursos renováveis e limites ao uso dos recursos nãorenováveis; d) Ambiental: respeito e realce à capacidade de autodepuração (capacidade de um corpo retornar às condições ecológicas iniciais) dos ecossistemas naturais; e) Territorial: balanceamento das configurações urbanas e rurais (eliminação das inclinações urbanas nas alocações do investimento público; melhoria do ambiente urbano; separação das disparidades inter-regionais e a criação de estratégias de desenvolvimento ambientalmente seguras para áreas ecologicamente frágeis - conservação da biodiversidade pelo ecodesenvolvimento); f) Econômico: promoção do desenvolvimento econômico intersetorial equilibrado; segurança alimentar; capacidade de modernização contínua dos instrumentos de produção; razoável nível de autonomia na pesquisa científica e tecnológica e inserção soberana na economia internacional; g) Política (nacional): efetivar a democracia definida em termos de apropriação universal dos direitos humanos; implantar o desenvolvimento da capacidade do Estado para implementar projeto nacional em parceria com todos os empreendedores e estimular um nível razoável de coesão social; h) Política (internacional): ampliar a eficácia do sistema de prevenção de guerras da Organização das Nações Unidas (ONU), na garantia da paz e na promoção da cooperação internacional; criar um pacote Norte-Sul de co-desenvolvimento, baseado no princípio de igualdade (regras do jogo e compartilhamento da responsabilidade de favorecimento do parceiro mais fraco); controle institucional efetivo do sistema internacional financeiro e de negócios; controle institucional efetivo da aplicação do princípio da precaução na gestão do meio ambiente e dos recursos naturais; prevenção das mudanças globais negativas; proteção da diversidade biológica (e cultural); e gestão do patrimônio global, como herança comum da humanidade; e a criação de um sistema efetivo de cooperação científica e tecnológica internacional e eliminação parcial do caráter de commodity da ciência e tecnologia, também como propriedade da herança comum da humanidade. (SACHS, 2002, p.85$88)$. 
Há que se preocupar, ainda, com a avaliação dos resultados dos empreendimentos sustentáveis, pois não raro as tomadas de decisões, nos âmbitos público e privado, deixam de internalizar os aspectos concernentes à sustentabilidade, prejudicando, de forma irrecuperável, o modelo de desenvolvimento que ora se defende. Tais aspectos configuram as dimensões do desenvolvimento, devendo ser examinados em suas relações mútuas, e implicando, assim, em um quadro unificado de planejamento para sua correta percepção e solução em todos os âmbitos (social, político, econômico e ambiental). Contribui para essa dificuldade o modelo cartesiano de dados, estatísticas, indicadores e de atribuição de preços, que desejam traduzir, monetariamente, os custos e benefícios sociais, ecológicos e culturais.

Sachs (2002) defende a elaboração de um relatório sobre a condição humana, de riqueza considerável e utilidade certa para a formulação das políticas públicas de desenvolvimento, centradas na promoção das quatro gerações dos direitos humanos.

E, é nesta esteira de raciocínio, que se abordará o tema "o mototaxismo como exemplo de um novo desafio para o transporte: a integração do desenvolvimento sustentável e território como modelo econômico includente", partindo da premente negligência do Estado para com o transporte público no país, deixando o problema para ser integralmente resolvido pela seara privada e/ou iniciativas de transportes outrora alternativos, todavia, fazendo-se imperioso esclarecer que o desenvolvimento, obrigatoriamente, deve ocorrer de forma sistêmica, para que não gere maiores abalos ao já frágil desenvolvimento posto.

\section{A negligência do Estado, transportes e o ecossociodesenvolvimento}

Apesar dos progressos espetaculares do crescimento material, ainda convive-se com o (re)questionamento do próprio conceito de desenvolvimento, fundando-se na justiça social em prol da criação de um homem novo.

O "ecossociodesenvolvimento" ou "ecossocioeconomia" requer a implementação de uma nova forma de atuação regional, buscando-se a geração de trabalho e renda de forma sustentável, inclusiva e participativa, considerando-se, nesse processo, as características locais e regionais, de natureza econômica, social, ambiental, institucional, política e cultural. Tal estratégia de desenvolvimento deve ser participativa e construtivista, baseada na conservação dos atores do processo, que é a própria comunidade. O modelo exige ação conjunta dos agentes das esferas federal, estadual e municipal, sociedade civil, políticos, empresários, profissionais liberais, entidades religiosas e Organizações Não-Governamentais - ONGs, 
dentre outros, em prol de um objetivo comum e maior, que é o desenvolvimento sustentável de sua região e do País.

A cooperação e a integração dos atores sociais é a força motriz para o êxito do modelo de desenvolvimento sustentável, pois ao comprometerem-se com objetivos comuns, tornam-se co-responsáveis, e promovem o desenvolvimento sustentável. Dessa forma, integrando a comunidade, o desenvolvimento sustentável, além de obter os resultados pretendidos que levam à universalização dos direitos humanos e fundamentais, propicia-se maior eficácia ao princípio da dignidade da pessoa humana e exige-se uma participação efetiva do Estado.

A Constituição da República Federativa do Brasil, de 1988, define um modelo econômico de bem-estar (arts. $1^{\circ}, 3^{\circ}$ e 170), tese defendida por Grau (2002), em sua obra "A Ordem Econômica na Constituição de 1988", em que ele sustenta a redefinição do papel do Estado após a promulgação da Carta Magna, contestando a atribuição do ônus social (aqui inclusas a educação, saúde, cultura e meio ambiente e, porque não dizer o transporte) ao setor privado, observe:

No que respeita à redefinição do papel do Estado, reclama-se a identificação de setores indevida e injustificadamente, do ponto de vista social, atribuídos ao setor privado - aqui as áreas da educação e da saúde - bem assim de outros nos quais vem [o Estado] atuando, como agente econômico, também do ponto de vista social, injustificada e indevidamente. (GRAU, 2002. p. 36).

Apesar da nítida necessidade e previsão da atuação do Estado, entende-se não ser possível a efetivação dos direitos fundamentais sem a ativa participação da sociedade. Nesse aspecto, reside a presente discussão, defendendo a integração das comunidades como ponto essencial para a eficácia desses direitos previstos pela Constituição e consagrados pela Declaração Universal dos Direitos Humanos, entendimento compartilhado por Sarlet (2004), ao lecionar que:

[...] no Estado social de Direito não apenas o Estado ampliou suas atividades e funções, mas também a sociedade cada vez mais participa ativamente do exercício do poder [...] É nesse contexto que assume relevo a dimensão jurídico-objetiva dos direitos fundamentais, de acordo com a qual estes exprimem determinados valores que o Estado não apenas deve respeitar, mas também promover e zelar pelo seu respeito, mediante uma postura ativa. (SARLET, 2004, p. 365).

Exatamente neste sentido, no que concerne especificamente ao transporte público, se evidencia, de maneira clara, a negligência do Estado quanto ao mesmo no Brasil. A ausência de políticas públicas voltadas para solucionar a questão, aliado ao propósito equivocado do 
Estado de atribuir ao setor privado, praticamente todo esse ônus possibilita o surgimento, dentre outros, do mototaxismo, que vem resolver um problema do próprio Estado.

Aqui, faz-se necessário explicitar a questão, levando-se em consideração a motocicleta, veículo que vem ganhando espaço ao longo do tempo como meio de transporte público individual, conforme destaca Fonseca (2005):

Independentemente do tamanho das cidades, o mototáxi surge como alternativa informal, clandestina, a um transporte coletivo precário ou mesmo inexistente. Apresentando vantagens como rapidez e preços reduzidos, ele atende sobretudo às demandas das classes de renda mais baixa, ao aliviar o peso do "transporte" em seu orçamento doméstico e ao garantir acesso a lugares não atendidos por ônibus, seja pela falta de pavimentação ou violência desses lugares, seja pela baixa lucratividade que oferece às empresas formais. Além de preços mais reduzidos, o serviço de mototáxi apresenta uma vantagem em comparação a outros serviços de transporte alternativo, como o de vans e kombis: a exclusividade do atendimento. Diferentemente destas modalidades de transporte, que têm percursos e horários determinados e operam com "lotada", o mototáxi se estrutura como um serviço personalizado, variando seus itinerários, preços e até formas de pagamento de acordo com o cliente. (FONSECA, 2005, p.57).

Ainda quanto à importância deste meio de transporte, lembra Fahel (2007) que

[...] é possível concluir que a motocicleta, no Brasil, representa um meio de transporte socialmente relevante para a população urbana, especialmente para a classe trabalhadora, que a utiliza, direta ou indiretamente, na sua vida diária - trabalho e escola. O seu custo acessível, inclusive de manutenção, a torna um instrumento, ainda que indireto, de profissionalização do trabalhador, contribuindo-lhe em mobilidade social, haja vista (e aqui estamos diante de uma conclusão óbvia) que o transporte coletivo, com destaque para o ônibus, apresenta uma limitação para conciliar trabalho e escola: a lentidão do sistema. Num desenvolvimento lógico de idéias, não é difícil afirmar que a facilidade de aquisição da motocicleta, o baixo de custo de manutenção e a economia com combustível, aliado a fatores como desemprego, falta de profissionalização do trabalhador brasileiro e, ainda, as conhecidas deficiências do transporte coletivo, criaram um ambiente propício para o desenvolvimento de um serviço alternativo de transporte: o mototáxi. (FAHEL, 2007, p. 1).

Daí a imersão, no campo da economia, se fazer obrigatório na presente discussão, como melhor forma de se explicar as causas da negligência do Estado para com o transporte público no país e, o mais importante, a maneira adequada de se entender e aprimorar o desenvolvimento em curso.

É inegável que a Geografia dos Transportes e a multidisciplinariedade caminham juntas, conforme a lição dos célebres autores Hoyle e Knowles (2001, p. 5), na qual eles afirmam que

[...] o estudo dos transportes é, sobretudo, multidisciplinar por natureza, e algumas vezes também interdisciplinar. Campos de 
pesquisa e atividades como a economia do transporte e direito do transporte são necessariamente complementares [...].

Santos (1986, p. 186), por sua vez, concorda com o entendimento supracitado, quando afirma que "Na verdade, o princípio da interdisciplinaridade é geral a todas as ciências [...]".

Nesse aspecto deve ser enfatizada a endogenia, pois o ecossociodesenvolvimento induz ao planejamento local e participativo, no nível micro das autoridades locais, comunidades e associações de cidadãos. Sachs (1993) vincula a esses agentes um papel central no planejamento e monitoramento da estratégia, o que aumenta nas pessoas o sentimento de pertencimento à sua evolução econômica e social, como verdadeiros atores do desenvolvimento. Isso reflete positivamente no aspecto democrático seguido por nosso Estado, formando cidadãos mais conscientes de seu papel, mais atuantes, com melhor qualidade de vida e até mesmo mais dignos. O entendimento exposto também é compartilhado por Silva (1987, p. 41): "No âmbito da crise do Estado Social se constata uma tendência cada vez maior no sentido de uma descentralização e distribuição do poder entre as forças sociais $[\ldots] ”$.

Exemplo de planejamento participativo é o Projeto de Política Nacional de Apoio ao Desenvolvimento Local, elaborado nos anos de 2005 e 2006 pelo Instituto Cidadania, que reuniu especialistas reconhecidos nacionalmente e representantes de importantes organismos e instituições que se dedicam ao tema do desenvolvimento sustentável no Brasil. O projeto visa propor uma inovadora Política Nacional de Apoio ao Desenvolvimento Local, tendo em vista que há muito tempo já crescia o consenso em torno da importância de se implementar ações com vistas a desbloquear e dinamizar as iniciativas autônomas de desenvolvimento, concebido sob o enfoque local. A proposta evidencia que é preciso reconhecer que os excluídos do processo de produção foram, na verdade, privados das oportunidades a que têm direito e que oportunidades se organizam e se multiplicam. É uma aposta na capacidade produtiva da base social do país, como fator essencial no atual processo histórico de reconstrução nacional, pois "os pobres não vivem em situação precária por falta de criatividade ou vontade, mas por insuficiência e pouca articulação dos sistemas de apoio". (INSTITUTO CIDADANIA, 2006, p. 12).

Novamente, a figura do mototáxi, se apresenta de maneira contundente. Pode-se, facilmente, exemplificar pela cidade de Ituiutaba, Minas Gerais. O desemprego em uma cidade do interior do Estado de Minas Gerais, que se encontra muito próxima de Uberlândia, uma cidade pólo que atrai a maioria esmagadora dos investimentos, somando-se ao 
crescimento exclusivo de trabalho na área rural (exploração de cana-de-açúcar) e à lacuna existente no transporte público local, em que o transporte público coletivo é ineficiente e o serviço de táxi muito caro para uma população carente que necessita de se locomover para fim precípuo de trabalho e estudo, possibilita o surgimento desta forma de transporte público individual em meados de 1997. O serviço atua de forma totalmente clandestina por cerca de três anos, quando, em 2000, devido à proliferação desordenada de serviços de transporte de passageiros em motocicletas, que constituiu esse modo de locomoção num fato irreversível naquela municipalidade, bem como, por pressões da própria população, que necessita deste meio de transporte, faz com o Município editasse o Decreto n. 4.666 de 26 de junho de 2000, o qual regulamenta a permissão do exercício desta atividade econômica, visando proteger os próprios usuários deste sistema e, igualmente, apresentando critérios mais rígidos quanto à segurança e à saúde pública.

Para se ter uma noção sócio-econômica dos operadores do serviço de mototaxismo na comarca de Ituiutaba, Estado de Minas Gerais, realizou-se uma entrevista com 104(cento e quatro) dos 250(duzentos e cinquenta) mototaxistas operantes (segundo dados do órgão responsável pelo planejamento, gestão e físcalização do transporte público no município de Ituiutaba, Departamento de Trânsito e Transportes, criado em 02/01/05), espalhados por 22 pontos de mototaxismo, traçando-se o perfil do operador e do serviço.

Os operadores são predominantemente do sexo masculino, conforme tabela 1, e nas projeções feitas nas tabelas 2, 3 e 4 pode-se verificar que a maioria dos operadores se encontram com idades entre 26 e 35 anos, mais da metade não teve acesso ao ensino médio e que o desemprego foi a mola propulsora para o início das atividades.

Tabela 1 - Município de Ituiutaba. Operador por sexo: 2009.

\begin{tabular}{ccc}
\hline Sexo & Número absoluto (n) & Porcentagem (\%) \\
\hline Masculino & 96 & $92,3 \%$ \\
Feminino & 8 & $7,7 \%$ \\
\hline Total & 104 & $100,00 \%$ \\
\hline
\end{tabular}

Org.: Emerson Gervásio de Almeida (2009)

Fonte: Entrevista realizada em Abril/Maio (2009). 
Tabela 2 - Município de Ituiutaba. Faixa etária dos mototaxistas: 2009.

\begin{tabular}{ccc}
\hline Faixa etária & Número absoluto (n) & Porcentagem (\%) \\
\hline Até 25 anos & 12 & $11,5 \%$ \\
26 a 35 anos & 52 & $50,0 \%$ \\
36 a 45 anos & 31 & $29,8 \%$ \\
46 a 50 anos & 3 & $2,9 \%$ \\
Mais de 50 anos & 6 & $5,8 \%$ \\
\hline Total & 104 & $100,00 \%$ \\
\hline
\end{tabular}

Org.: Emerson Gervásio de Almeida (2009)

Fonte: Entrevista realizada em Abril/Maio (2009).

Tabela 3 - Município de Ituiutaba. Nível de escolaridade dos mototaxistas: 2009.

\begin{tabular}{ccc}
\hline Nível de escolaridade & Número absoluto (n) & Porcentagem (\%) \\
\hline Ensino Fundamental incompleto & 16 & $15,4 \%$ \\
Ensino Fundamental completo & 58 & $55,8 \%$ \\
Ensino Médio incompleto & 4 & $3,8 \%$ \\
Ensino Médio completo & 26 & $25,0 \%$ \\
Ensino Superior incompleto & 0 & 0 \\
Ensino Superior completo & 0 & 0 \\
\hline Total & 104 & $100,00 \%$ \\
\hline
\end{tabular}

Org.: Emerson Gervásio de Almeida (2009)

Fonte: Entrevista realizada em Abril/Maio (2009).

Tabela 4 - Município de Ituiutaba. Motivo ensejador do início das atividades enquanto mototaxista: 2009.

\begin{tabular}{ccc}
\hline Motivo & Número absoluto (n) & Porcentagem (\%) \\
\hline Desempregado & 64 & $61,50 \%$ \\
Melhor remuneração & 13 & $12,50 \%$ \\
Flexibilidade de horário & 10 & $9,60 \%$ \\
Falta de opção & 8 & $7,70 \%$ \\
Outros & 9 & $8,70 \%$ \\
\hline Total & 104 & $100,00 \%$ \\
\hline
\end{tabular}

Org.: Emerson Gervásio de Almeida (2009) 
Fonte: Entrevista realizada em Abril/Maio (2009).

O levantamento identificou, ainda, dados sociais importantes acerca do meio dos mototaxistas em Ituiutaba/MG, entre eles, a baixa remuneração apesar da exaustiva jornada de labor diário, o que facilmente se identifica pelas tabelas 5 e 6 , respectivamente.

Tabela 5 - Município de Ituiutaba. Valor médio da remuneração mensal dos mototaxistas: 2009.

\begin{tabular}{ccc}
\hline Remuneração & Número absoluto (n) & Porcentagem (\%) \\
\hline Até 1 salário mínimo & 4 & $3,80 \%$ \\
1 a 2 salários mínimos & 94 & $90,44 \%$ \\
2 a 3 salários mínimos & 5 & $4,80 \%$ \\
Acima de 3 salários mínimos & 1 & $0,96 \%$ \\
\hline Total & 104 & $100,00 \%$ \\
\hline
\end{tabular}

Org.: Emerson Gervásio de Almeida (2009)

Fonte: Entrevista realizada em Abril/Maio (2009).

Tabela 6 - Município de Ituiutaba. Horas trabalhadas diariamente: 2009.

\begin{tabular}{ccc}
\hline Horas & Número absoluto (n) & Porcentagem (\%) \\
\hline Menos 8 horas & 2 & $1,92 \%$ \\
De 8 a 10 horas incompletas & 6 & $5,80 \%$ \\
De 10 a 12 horas & 82 & $78,83 \%$ \\
Acima de 12 horas & 14 & $13,45 \%$ \\
\hline Total & 104 & $100,00 \%$ \\
\hline
\end{tabular}

Org.: Emerson Gervásio de Almeida (2009)

Fonte: Entrevista realizada em Abril/Maio (2009).

Resta claro que a efetivação da responsabilidade estatal em prover a sociedade dos diversos direitos fundamentais está intrinsecamente ligada ao desenvolvimento, entendido como universalização desses direitos. Ora, o Estado deveria estar mais atento aos problemas sociais intrínsecos aos mototaxistas, conforme apresentado acima, como por exemplo, a baixa escolaridade dos mesmos, assim como, ao incentivo ao início dessa atividade, quer seja, o desemprego. Conforme o Instituto Cidadania (2006, p. 81): “[...] ajudar as comunidades a se ajudarem não livra o Estado de sua responsabilidade, pelo contrário, gera uma comunidade 
mais participativa, consciente e capaz de exigir e de controlar". E isto, é exatamente o que se espera de um Estado Democrático de Direito, que oportunize o crescimento a todos, trazendo benefícios às diversas formas de comunidade que o compõem e não, apenas, como um figurante dessa situação, que não gera mecanismos capazes de estímulos eficazes.

Enfim, para que se obtenha o efeito pretendido, é necessário que o planejamento do desenvolvimento permeie as cinco dimensões do conceito de sustentabilidade: sustentabilidade social, sustentabilidade econômica, sustentabilidade ecológica, sustentabilidade espacial e sustentabilidade cultural; e, é nesta ótica, que se apresentam as diretrizes do desenvolvimento, tendo como pano de fundo, o uso do território em si mesmo, como objeto da análise social, apresentada aqui pelo ingresso dos mototaxistas no espaço urbano local.

\section{Diretrizes do desenvolvimento e território}

A implementação de um modelo de desenvolvimento sustentável pressupõe, ainda, algumas diretrizes essenciais para sua formatação e implementação. É necessária uma visão de cadeia de valor, mais integrada e sistêmica acerca do processo produtivo, qualquer que seja a atividade de determinada região. A visão, antes segmentada, torna impossível a produção, devendo-se compreender, ainda, a interdependência e a necessidade de articulação para o sucesso num mercado cada vez mais globalizante. A construção dessa visão exige conhecimento de todos os atores sociais envolvidos e dos estágios-chave das atividades.

A estratégia deverá atender a uma visão de futuro, que significa avaliar a capacidade que a atividade tem ou possa vir a ter de se perpetuar do ponto de vista econômico, espacial, ambiental, social, jurídico e cultural. Deve ser visto numa dimensão de longo prazo, sem, contudo, estabelecer critérios rígidos para classificar estas dimensões, adequando-se os objetivos com a quantificação de tempo e nível de mudança a que se pretende chegar.

Organizar o processo de desenvolvimento também é importante, ordenando as regiões através de suas necessidades específicas. Esse aspecto é definido como visão de abrangência, e nesse sentido está a utilização do conceito de território voltado para as ações. Isso porque o território é o centro das estratégias que visam à competitividade e atratividade econômica, reforçando a coesão social e configurando um excelente instrumento de modernização das políticas públicas. Apesar de nele estarem ancoradas as instituições locais, permanece um domínio de ação de instâncias hierárquicas superiores cujos graus de liberdade são cada vez 
mais condicionados pelo processo de globalização e pela construção de acordos regionais supranacionais.

Para Haesbaert (2004, p. 79) é evidente a necessidade de uma visão de território “[...] a partir da concepção de espaço como um híbrido - híbrido entre sociedade e natureza, entre política, economia e cultura, e entre materialidade e 'idealidade' [...]".

Em resumo, é a combinação da concorrência com cooperação, conflito com participação e conhecimento local e prático com o científico. Trata-se da existência de um sentimento de pertencimento e, mais do que isso, de um plano territorial assumido pelos atores sociais, levando a um nível muito elevado de organização do território, que tende a favorecer o seu desenvolvimento.

Para Santos (1994 apud Balbim 1996, p. 163) tem-se que “[...] é o uso do território em si mesmo, que faz dele objeto da análise social. Trata-se de uma forma impura, um híbrido, uma noção que, por isso mesmo, carece de constante revisão histórica." Dentre as potencialidades que devem ser identificadas no processo temos a capacidade que o desenvolvimento terá de gerar oportunidades negociais para todas as partes envolvidas. Assim, tem-se a análise do caráter da viabilidade econômica, as condições para aumentar a produtividade, a capacidade de absorção de novas tecnologias com ampliação dos níveis de ocupação de mercado, a própria existência de mercado para absorver maior volume de produção e novos produtos e a capacidade dos agentes locais de agregarem valor participando dos demais elos da cadeia. Ocupar as comunidades significa elevar o potencial de geração de trabalho e renda, fortalecendo o comércio local; e isto efetivamente ocorreu em Ituiutaba, com o início das atividades do mototaxismo.

Tudo isto pode ser evidenciado no brilhante entendimento acerca de Geopolítica apresentado por Vlach (2008), senão vejamos:

Exercer a cidadania é, pois, atuar politicamente, resgatando os debates em praça pública, vendo-se a si mesmo e ao Outro como Seres humanos indivisos, livres, iguais, para os quais a idéia de território faz sentido na medida em que os leva a refletir sobre a sua fragilidade. Fica claro que o seu grande desafio é o de construir uma convivência democrática e cosmopolita na Terra, onde a complexidade dos diversos territórios pode ser respeitada por essa nova Geopolítica, que se compromete com ações políticas democráticas no conjunto do tecido social, ameaçado pela banalização da violência internamente e pela progressão de atos terroristas na arena mundial, assim como pelo desrespeito às condições ambientais, o que ilustra perfeitamente a arrogância humana no reduzir a Terra a um objeto de exploração. (VLACH, 2008, p. 9). 
Promover o desenvolvimento sustentável, com sua essencial regionalização, não é uma tarefa exclusiva do Estado, empresas ou qualquer outra organização, de forma individual, mas do conjunto da sociedade em todas as suas formas. Posto isso, chega-se à idéia de que as forças sociais unidas têm maiores possibilidades de mudar a realidade dos espaços no qual vivem e se desenvolvem e, somente desta forma, poder-se-á utilizar o serviço de transporte individual por motocicleta de maneira adequada.

\section{Considerações finais}

O atual modelo de crescimento econômico gerou enormes desequilíbrios; se, por um lado, nunca houve tanta prosperidade no mundo, por outro lado, a miséria, a degradação ambiental, os congestionamentos e a má distribuição da renda aumentam cotidianamente, o que possibilitou o nascimento, dentre outros, da figura do mototáxi, fruto da negligência do Estado para o cidadão e, especificamente, para com o transporte público. Diante desta constatação, surge a idéia do desenvolvimento sustentável, buscando conciliar o desenvolvimento econômico com a preservação ambiental e, ainda, ao fim da pobreza no mundo.

Requer-se um pensamento além do simples crescimento econômico baseado na acumulação de riquezas, mas uma noção sistêmica e participativa de universalização dos direitos humanos e fundamentais, objeto do Estado Democrático de Direito.

Ainda, integrar as comunidades é fator de extrema relevância, que aponta para um modelo includente e, destarte, mais eficaz, com a racionalização dos esforços para o objetivo comum de um verdadeiro desenvolvimento integral e sistêmico, sem segmentações e exclusão social. E os transportes não fogem desta forma sustentável de evolução. Daí, inclusive, a necessidade de conhecer os diversos meios de transportes, particularmente, o mototaxismo, figura nova em nosso meio, todavia, já presente no cotidiano dos cidadãos brasileiros. Eis então, o grande desafio, integrar o desenvolvimento sustentável com o território - este entendido em seu sentido mais amplo e, não apenas em sua perspectiva materialista - como forma de expressar um modelo econômico includente.

A descentralização do poder e a regionalização são fatores também essenciais para o novo modelo de desenvolvimento, combinando a idéia de território com a idéia de domínio coletivo, onde estão presentes e se combinam as condições e forças internas e externas de uma totalidade especial fundamentais para o desenvolvimento sustentável. 
A participação dos agentes também se traduz em uma concreta forma de exigir e controlar a atuação estatal, aumentar o sentimento de pertencimento social e de criar uma sociedade mais consciente de seu papel, responsável pela sua evolução e construtora de seu próprio desenvolvimento e, o mototaxismo não foge a esta regra, pelo contrário, tem de ser encarado como um importante objeto de análise social, para que o Estado tente obter o almejado desenvolvimento integral.

\section{Referências}

BALBIM, R. N. Região, território, espaço: funcionalização e interfaces. In: CARLOS, A. F. A. (org.). Ensaios de geografia contemporânea: Milton Santos obra revisitada. São Paulo: Hucitec, 1996. p. 160-169.

BRASIL. Constituição da República Federativa (1988). Lex: Vade Mecum. 3. ed. São Paulo: Saraiva, 2007.

DECLARAÇÃO UNIVERSAL DOS DIREITOS HUMANOS. Assembléia Geral das Nações Unidas, 1948. Adotada e proclamada pela resolução 217 A (III).

FAHEL, M. J. C. Serviço de mototáxi: postura do Ministério Público. Jus Navigandi, Teresina, ano 11, n. 1528, 7 set. 2007. Disponível em: $<$ http://jus2.uol.com.br/doutrina/texto.asp?id=10386>. Acesso em: 24 maio 2009.

FONSECA, N. R. R. da. Sobre duas Rodas: o mototáxi como uma invenção de mercado. 2005. 113 p. Dissertação (Mestrado em Estudos Populacionais e Pesquisas Sociais) Programa de pós-graduação em Estudos Populacionais e Pesquisas Sociais da Escola Nacional de Ciências Estatísticas ENCE/IBGE, 2005. Disponível em: $<$ http://www.ence.ibge.gov.br/pos_graduacao/mestrado/dissertacoes/pdf/2005/natasha_reis_d a_fonseca_TC.pdf>. Acesso em: 27 ago. 2009.

GRAU, E. R. A Ordem Econômica na Constituição de 1988. São Paulo: Malheiros, 2002.

HAESBAERT, R. O mito da desterritorialização. Do "fim dos territórios" à multiterritorialidade". Rio de Janeiro: Bertrand Brasil, 2004.

HOYLE, B.; KNOWLES, R. Modern transport geography. (Edition 2). Chichester-UK: John Wiley \& Sons Ltd, 2001.

INSTITUTO CIDADANIA. Projeto Política Nacional de Apoio ao Desenvolvimento Local. São Paulo. 2006.

ITUIUTABA. Decreto $n^{\circ} 4.666$, de 26 de junho de 2000 - Regulamenta a permissão do transporte individual moto-táxi e dá outras providências.

SACHS, I. O problema da democracia econômica e social. In: Comissão de Assuntos Econômicos, 1993. Brasília: Senado Federal, 1993. p. 10. 

2002 .

Caminhos para o desenvolvimento sustentável. 4. ed. Rio de Janeiro: Garamond, O desenvolvimento enquanto apropriação dos direitos humanos. Estudos Avançados, São Paulo, v. 12, n. 33, 1998. p. 149-156.

SANTOS, M. Por uma geografia nova. 3. ed. São Paulo: Hucitec, 1986.

SARLET, I. W. A Eficácia dos Direitos Fundamentais. 4. ed. Porto Alegre: Livraria do Advogado, 2004.

SILVA, C. L. da (Org.). Desenvolvimento sustentável: um modelo analítico integrado e adaptativo. Petrópolis: Vozes, 2006.

SILVA, M. P. D. P. da. Vinculação das Entidades Privadas pelos Direitos, Liberdades e Garantias. In: Revista de Direito Público. n. 82, 1987.

SOUZA, M. L. de. ABC do desenvolvimento urbano. 2. ed. Rio de Janeiro: Bertrand Brasil, 2005.

VIEIRA. P. F. (Org.). Rumo à Ecossocioeconomia: teoria e prática do desenvolvimento. São Paulo: Cortez, 2007.

VLACH, V. O estado-nação moderno na contemporaneidade: um outra geopolítica. Scripta Nova. Revista Electrónica de Geografía y Ciencias Sociales. Barcelona: Universidad de Barcelona, 1 de agosto de 2008, vol. XII, núm. 270 (32). Disponível em $<$ http://www.ub.es/geocrit/sn/sn-270-32.htm>. Acesso em: 19 abr. 2009.

ZAPATA, T. Desenvolvimento humano. Instituto de Assessoria para o Desenvolvimento Humano (IADH). Recife, 2006. Disponível em <http://www.iadh.org.br/>. Acesso em: 21 mar. 2009. 